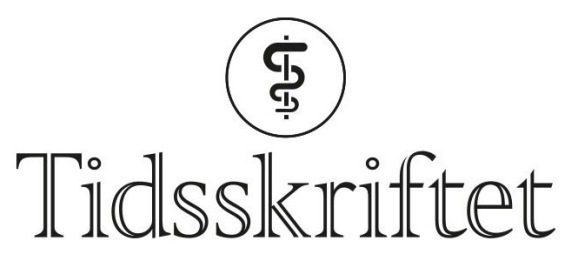

DEN NORSKE LEGEFORENING

\title{
Uttrykket medisinsk cannabis er utdatert
}

SPRÅKSPALTEN

TROND TRATTEBERG SERKLAND

E-post: trond.tretteberg.serkland@helse-bergen.no Trond Trætteberg Serkland er lege i spesialisering ved Seksjon for klinisk farmakologi, Avdeling for medisinsk biokjemi og farmakologi, Haukeland universitetssjukehus.

\section{THOMAS PAHR}

Thomas Pahr er konstituert overlege ved Divisjon Psykisk helsevern, Avdeling Østmarka, St. Olavs hospital.

\section{INGRID ANNA TEIGEN}

Ingrid Anna Teigen er lege i spesialisering ved Seksjon for klinisk farmakologi, Avdeling for medisinsk biokjemi og farmakologi, Haukeland universitetssjukehus.

\section{JON ANDSNES BERG}

Jon Andsnes Berg er overlege ved Seksjon for klinisk farmakologi, Avdeling for medisinsk biokjemi og farmakologi, Haukeland universitetssjukehus.

Uttrykket medisinsk cannabis er mye brukt, men det kan være direkte misvisende. Vi anbefaler en mer presis terminologi. 


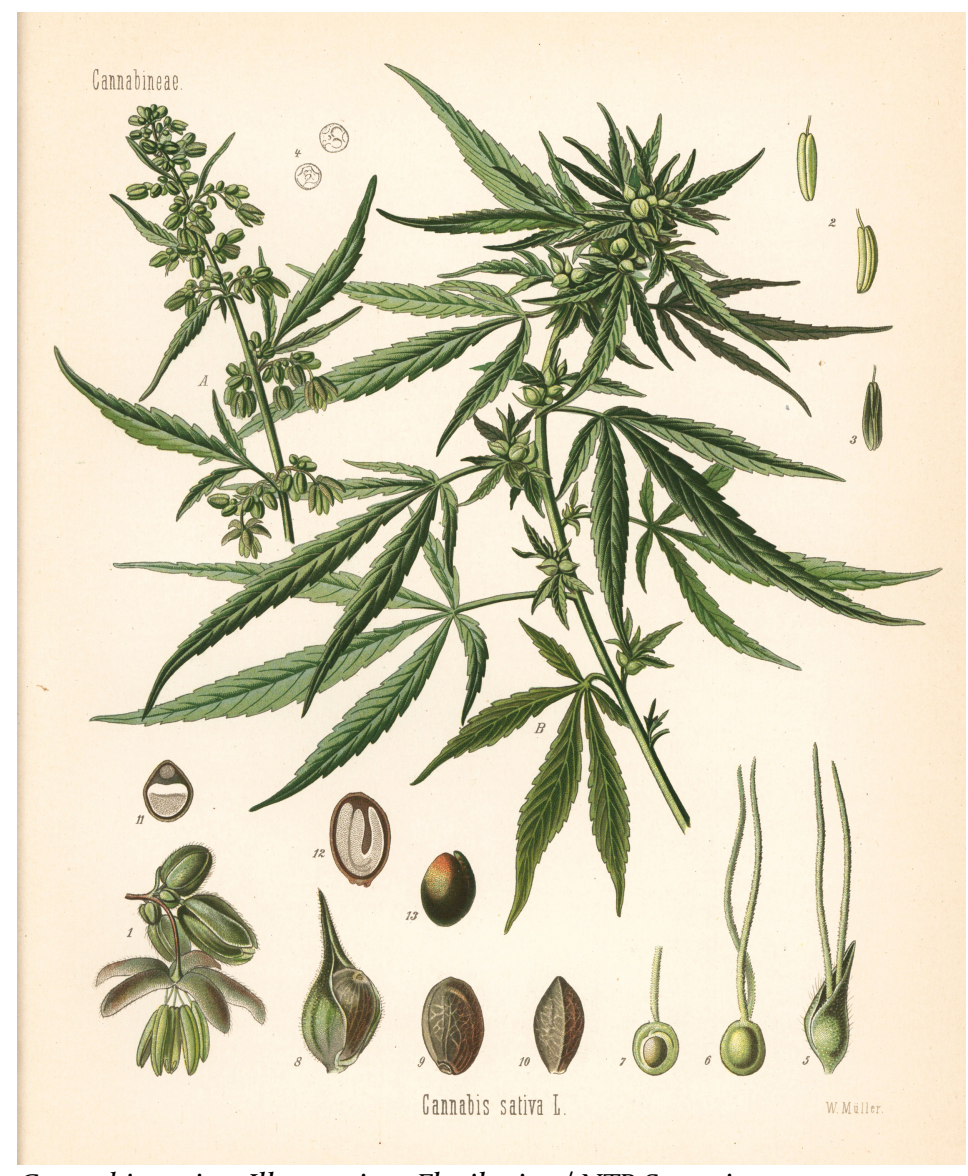

Cannabis sativa. Illustrasjon: Florilegius / NTB Scanpix

Cannabisprodukter til medisinsk bruk har fått stor oppmerksomhet i de siste årene. Samtidig har bruken av uttrykket medisinsk cannabis bredt om seg. Termen gir mening dersom formålet er å skille anvendelse på medisinsk indikasjon fra illegal bruk, men sier lite om hvilket preparat eller produkt det er snakk om. Noen ganger er slik ordbruk misvisende. Vi mener at en mer presis nomenklatur må på plass.

\section{Planter som legemidler}

Planter har blitt brukt som legemidler til alle tider (1). Med utviklingen av kjemi som vitenskap har man klart å ekstrahere ulike farmakologisk virksomme substanser i planter, slik som digoksin fra Digitalis purpurea, atropin fra Atropa belladonna og salisylsyre fra Salix alba.

Valmueplanten Papaver somniferum er et illustrerende eksempel. Ved å skjære et snitt i en moden valmue renner en hvit saft ut, som har fått navnet opium (2). Saften inneholder en mengde farmakologisk aktive substanser inkludert morfin, kodein, noskapin og papaverin. Dette planteproduktet har trolig vært i medisinsk bruk i minst 3 ooo år (3). I 1804 ble morfin isolert, og dette var starten på utviklingen av legemidler med én virksom farmakologisk substans. Nomenklaturen fulgte med. Ingen snakker om medisinsk opium. Substansene som binder til kroppens opioidreseptorer, kalles opioider (2).

\section{Cannabis}

Cannabis sativa er en annen plante med en 3 ooo år gammel historie med medisinsk anvendelse (4). Cannabis er en samlebetegnelse på materiale fra denne planten, herunder blant annet marihuana, hasj og cannabisolje. Cannabis sativa inneholder flere hundre ulike kjemiske substanser, der rundt 80 er vist å ha effekt på cannabinoidreseptorer (5). Disse kalles cannabinoider. I 1960-årene ble cannabinoidet tetrahydrocannabinol (THC) isolert. Senere har også flere andre cannabinoider blitt isolert, som cannabidiol (CBD) og cannabinol (CBN), og THC-analoger har blitt syntetisert. 
Det er økende interesse for legemidler med utgangspunkt i cannabisplanten.

Nomenklaturen har imidlertid ikke fulgt med. Begrepet medisinsk cannabis er i utbredt bruk, også i artikler publisert i Tidsskriftet og en nylig oppdatert prosedyre fra Statens legemiddelverk $(6,7)$. Det er imidlertid ikke entydig hva dette refererer til. En rekke andre mer eller mindre overlappende uttrykk brukes også: cannabisrelaterte legemidler, cannabisprodukter, medisinsk marihuana, derivater av cannabis etc. Uttrykket medisinsk marihuana er i USA sågar blitt brukt til å fremme legalisering (6).

Legemidlene som faller inn under paraplybetegnelsen medisinsk cannabis, er heterogene og brukes ved ulike indikasjoner. Her er noen eksempler (representert ved handelsnavn, kun Sativex er registrert i Norge):

- Sativex: Ekstrakt fra cannabisplanten, inneholder CBD og THC. Indikasjon (i Norge): spastisitet ved multippel sklerose.

- Epidiolex: Planteekstrakt renset for THC, inneholder CBD. Indikasjon (i USA): Epileptiske anfall knyttet til Lennox-Gastauts syndrom og Dravets syndrom.

- Marinol: Syntetisk framstilt THC (dronabinol). Indikasjoner (i USA): Tap av matlyst hos pasienter med aids, kvalme og oppkast ved kjemoterapi.

Vi mener det er tvetydig og misvisende å referere til alle disse som medisinsk cannabis, eller å bruke noen av de andre uttrykkene referert ovenfor. Det vil være som å kalle alle opioidene for medisinsk opium. Vi observerer også at uttrykket i enkelte sammenhenger brukes til å skille preparatene som inneholder cannabisplanten som sådan, for eksempel produkter fra Bedrocan (7), fra ekstrakter fra cannabisplanten. Medisinsk refererer til konteksten den farmakologisk aktive substansen brukes i. Et legemiddel bør få navn ut fra hvilket virkestoff det inneholder, ikke konteksten det skal brukes i.

\section{Konklusjon}

Som en parallell til opioider vil begrepet cannabinoider romme alle substanser som binder til cannabinoidreseptorer. Vi tar derfor til orde for en mer presis begrepsbruk: Bruk cannabinoider som fellesbetegnelse på alle legemidler som har cannabinoidreseptor som primært virkested, med de tre spesifikke undergruppene: cannabis, naturlig cannabinoid og syntetisk cannabinoid (tabell 1).

\section{Tabell 1}

Undergrupper av cannabinoidholdige preparater.

\begin{tabular}{|lll|}
\hline Uttrykk & Beskrivelse & Eksempel på produkt \\
\hline Cannabis & Plantemateriale & Bedrocan \\
\hline Naturlig cannabinoid & $\begin{array}{l}\text { Ekstrahert og/eller isolert cannabinoid fra } \\
\text { planten }\end{array}$ & Sativex \\
\hline Syntetisk cannabinoid & Kjemisk fremstilt cannabinoidanalog & Marinol \\
\hline
\end{tabular}

${ }^{1}$ Dette må defineres som et kombinasjonspreparat siden det inneholder to ulike cannabinoider

1. Norsk legemiddelhåndbok for helsepersonell. Plantebaserte legemidler og naturlegemidler. https://www.google.com/url?sat\&rctj\&q=\&esrcs\&sourceweb\&cd=1\&cad- 
rja\&uact=8\&ved=2ahUKEwjxkOiKzZPkAhVswsQBHaHNCB8QFjAAegQIAxAB\&url-

http\%3A\%2F\%2Flegemiddelhandboka.no\%2FGenerelle\%2Fs\%25 $\mathrm{C}_{3} \% 25$ B8ker\%2F\%2B\%252BMedisinsk\%2F16 o637\&usgAOvVaw2GqQVqPecqziCkDjQWj5iK\&cshid=1566378178472876 Lest 21.5.2019.

2. Westin AA, Strøm EJH, Slørdal L. Opiat eller opioid? Tidsskr Nor Legeforen 2011; 131:1320-1. [CrossRef]

3. Torp HA, Gustavsen I, Romundstad L. En botanisk anestesi. Tidsskr Nor Legeforen 2017; 137. doi: 10.4045/tidsskr.17.0659. [PubMed][CrossRef]

4. Khiabani HZ, Mørland J. Cannabis og cannabinoider som legemidler. Tidsskr Nor Lægeforen 2007; 127: 579-82. [PubMed]

5. Store medisinske leksikon. Cannabis. https://sml.snl.no/cannabis Lest 21.5.2019.

6. Bramness JG. Cannabis som medisin. Tidsskr Nor Legeforen 2015; 135: 252-3. [PubMed][CrossRef]

7. Statens Legemiddelverk. Prosedyre for behandling med medisinsk cannabis innenfor dagens regelverk.

https://legemiddelverket.no/bivirkninger-og-sikkerhet/rad-til-helsepersonell/behandling-med-medisi nsk-cannabis-innenfor-dagens-regelverk Lest 21.5.2019.

Publisert: 27. august 2019. Tidsskr Nor Legeforen. DOI:10.4045/tidsskr.19.0224

(C) Tidsskrift for Den norske legeforening 2020. Lastet ned fra tidsskriftet.no 